Author: Phil Parvin. Article published online on Aug $12^{\text {th }} 2019$ by Ethnicities.

\title{
When The People Are Not Reasonable: Multiculturalism And Realistic Normative Theory in the Contemporary Era
}

Multiculturalism is once again moving to the foreground of Anglo-American political philosophy, as political philosophers revisit questions of cultural recognition, minority rights, and identity and also the ways in which theories of public reason, originating in Rawls's later work, might be applied to questions of diversity (e.g. Gaus, 2012; Horton et al, 2018; Patten, 2014; Quong, 2010; Meer et al, 2016; Tebble, 2017). Political philosophers remain divided on the question of how the state should best respond to the fact of cultural and ethical diversity (e.g. Gray, 2000; Kukathas, 2003; Kymlicka, 1996; Laden \& Owen, 2007; Modood, 2013; Parekh, 2000; Thomassen, 2017). What we might call the 'first wave' of theorizing on this issue dominated political philosophy from the late 1980 s to the early 2000 s. The communitarian critique of liberal individualism forced many liberals to re-visit the philosophical bases of their own doctrine, and to acknowledge the many complex ways in which people's choices, their identities, their freedom, were shaped by attachments to historical communities that they didn't define or choose, but which nevertheless provided their perspective on the world (Maclntyre, 1981; Sandel, 1982). The importance of identityconferring communities, including cultural groups, was obvious in the expressed testimony of individuals around the world - from first nations and aboriginal peoples in New Zealand, Canada, and the USA, to immigrants across Europe - but challenging to liberal theory. The political philosophy mainstream couldn't capture, let alone resolve, the problems of the political mainstream.

The attempt by political philosophers to address this problem created a debate which quickly divided into multiple camps. Some 'comprehensive' liberals grounded their response to diversity in controversial principles like individual autonomy (Kymlicka, 1989; Raz, 1986). Other 'political' liberals rejected this approach for being too demanding of a diverse public 
(Rawls, 1991; Larmore, 1995; Nussbaum, 1999). And defenders of what might be broadly labelled a 'politics of difference' argued for a more radical vision, drawing on continental philosophy, post-structuralism, and critical theory in order to reject both comprehensive and political liberalism for their focus on individual rights and freedoms, and conventional distinctions between public and private (Taylor, 1994; Tully, 1995; Young, 1990 \& 2000). ${ }^{1}$

The first wave arguably culminated in a general consensus among many political philosophers that conventional liberal normative theory needed to be more attentive to the particular concerns of cultural minorities, either by incorporating identity claims directly into their theories, or by explaining more clearly why doing so was unnecessary (Kymlicka, 2007). Many politicians agreed, and many governments in Europe joined Canada in acknowledging the importance of cultural and religious attachments, and of enabling members of minority cultures to practice their beliefs freely through a combination of legal exemptions and financial support (Barry, 2000; Parvin, 2009).

The renewed interest in the challenges to political theory and practice posed by cultural and religious diversity, and the emergence of a 'second-wave' of multicultural theorizing, is easily explained: neither the discipline of political philosophy nor the politics of actually-existing states are what they were back during the first-wave of multiculturalism debates and the settled consensus among political philosophers about how to respond to questions of cultural and ethical diversity seem out of kilter with the world as it exists in the $21^{\text {st }}$ Century.

Within the discipline, disagreements about the nature of political philosophy, and its methods, have become increasingly dominant. Debates between ideal and non-ideal theorists, and between 'moralists' and political realists, about how realistic normative theorizing should be have fundamentally altered the practice (Sleat, 2018; Stemplowska \& Swift, 2012; Valentini, 2012). Outside the discipline the political landscape has changed profoundly in ways which exert pressure on enduring assumptions among political theorists 
about how liberal democratic states should resolve questions about immigration and diversity (Parvin, 2009 \& 2017). While commitment to some sort of multiculturalism has endured among many philosophers, many outside of academia have proclaimed the death of multiculturalism as a political project, following widespread concerns about radicalization, the growth of terrorism, and perceived negative social consequences of emphasizing difference over unity (Blair, 2004; Cameron, 2011; Parvin, 2009, 2018b; Phillips, 2004; Toynbee, 2004). The first two decades of the $21^{\text {st }}$ century have been particularly inhospitable to the high-minded ideals of multiculturalist political philosophers, whose theories now look disconnected from a world that has changed utterly. The populations of many states have become more critical of multiculturalism and more hostile to immigration. Populist movements in the USA and Europe have gained a larger and larger foothold in mainstream politics, kept at bay primarily by the fact that mainstream parties have themselves moved to the right and co-opted the anti-immigrant rhetoric and policies of the populists. And millions of UK citizens voted to leave the EU on the grounds that only through doing so could the UK protect its borders, culture, and public services from being swamped by immigrants and refugees. The old battlelines drawn in the first wave multiculturalist debate seem increasingly blurred and tenuous. We are living through a time in which the assumptions on which the dominant normative approaches to diversity are under stress. Many citizens of many liberal democratic states don't seem to value freedom, equality, or inclusivity for minority groups or immigrants. Assumptions long-held among academics about how people will think and act in political debates, and what they believe to be true, appear to be unfounded. The persuasiveness of normative theories grounded in these assumptions, and in the fact that values like freedom and equality are widely valued, has been profoundly weakened.

There is a sense in which normative theory always exists at odds with the real world commitments of actual citizens. But when theories are defended as potential solutions to real world problems - as political liberalism and the politics of difference are - it's reasonable 
to evaluate them in the context of real world circumstances; to ask, how effective these theories would be in resolving the problems they identify. And while there was never a golden historical moment characterised by a spirit of toleration and openness toward minorities, widespread attitudes on this issue across many liberal democratic states are more negative and exclusionary than they used to be. The settled conclusions arising out of first wave multiculturalism can't be applied to the world as it is currently configured. The political realities which characterize the early $21^{\text {st }}$ Century have revealed the weaknesses inherent in these assumptions, and their lack of purchase in a world which has moved away from toleration or recognition, toward hostility, inequality, and intolerance. This fact poses a fundamental challenge to political philosophers who view their theories as possible strategies for actual realistic political reform, and presents them with a choice. They can present a theory which is realistic in the sense that it takes account of political reality and offers a strategy which might be used to genuinely inform a process of reform. This option would require political philosophers to reject the grounding assumptions of the first-wave consensus among liberal and non-liberal thinkers, and instead build a theory from the materials that $21^{\text {st }}$ Century politics presents us with: a theory which doesn't require people to think or act in ways that they don't or can't, or which requires public attitudes to be other than what they are. Alternatively, they can continue to hold to the values embodied in the first wave consensus. But this option would require them to abandon realism and also the desire to produce an operational normative theory which can resolve real problems in actually-existing states. In essence, my claim is that recent work in contemporary political philosophy that has assumed that it's possible to defend a rich conception of justice (as defined by a loose commitment to certain ethical principles like freedom and equality) and democracy (Rawls, 1993 \& 2001; Gutmann \& Thompson, 2004), or to argue that justice and democracy require one another, or that democracy is the best way of producing a conception of justice in the real world (e.g. Van Parijs, 2011; Young, 2000), are weakened by political developments in the contemporary era. 
My aim is to explain why political philosophers, and politicians, face this choice, and to trace some of its implications for both contemporary politics and the discipline of political philosophy. I do so first by outlining the ways in which political liberalism and the politics of difference - arguably the two theories which dominated first-wave debates - share background assumptions which are inapplicable in the contemporary era. I do so first by reconstructing the first wave debate between political liberals and defenders of a politics of difference with a view to evaluating their strengths and weaknesses in the current political and disciplinary context, focusing on Rawls's political liberalism and Iris Marion Young's theory of a politics of difference as exemplars of these approaches. I present both approaches in what I take to be their most persuasive light: as theories which both, in their own ways, genuinely seek to offer solutions to concrete problems in actually-existing states, and offer a vision of political practice which can respond to the political tension caused by cultural and ethical diversity (sections 1 and 2). I then argue that neither approach is able to provide a solution to these tensions because they are both grounded in an unsustainable vision of political elites and ordinary citizens as able to engage in forms of reasoning that they can't engage in, and to hold to values that they don't hold to (section 3). I thus argue that the two major normative approaches which characterised first wave debates about how best to resolve questions of cultural and ethical diversity are more realistic than some critics have suggested, but that, even when presented in their most realistic light, are untenable in the contemporary era. Having done so, I suggest (in section 4) that this fact presents political theorists with a stark choice: abandon theories which foreground democratic dialogue of the kind found in political liberalism and the politics of difference, or retain the dialogical model but reconfigure the process of dialogue in ways which fit the real world and the people who live in it. To put it another way: in the contemporary era, philosophers can either provide a normative theory which is realistic, which will be democratic and not very just, or one which is unrealistic, which will be just but not very democratic. 


\section{Political liberalism as realistic moralism: the strategy of privatization.}

The politics of difference and political liberalism are variants of the same normative approach to cultural and ethical diversity. In order to see why, and hence why they are both flawed, we need to discuss the ways in which they are commonly held to be distinct. One way of capturing the difference between them, proposed by Brian Barry, is in the fact that one seeks to 'privatize' difference while the other seeks to 'politicize' it (Barry, 2000). Political liberals are committed to the privatization of difference in order to produce political outcomes which are fair, and to establish a basic regime of equal liberties which are 'difference-blind' in the sense that they apply to all people regardless of their particular beliefs or conceptions of what makes life valuable (Larmore, 1987 \& 1995; Macedo, 2000; Nussbaum, 1999; Okin, 1994; Quong, 2010; Rawls, 1993 \& 2001). Difference theorists, on the other hand, seek to politicize these moral, cultural, or ethical roles, claiming that an inclusive politics must necessarily incorporate identity claims if it is to produce outcomes which are non-exclusionary (Young, 1990, 2000; Taylor, 1994; Tully, 1995). John Rawls and Iris Marion Young are arguably the most influential and recogniseable exemplars of these alternative views. Both ground their theories in a particular model of political dialogue which they intend to be understood as a guide for real-world political actors to deliberate on political questions, either individually or collectively. Young explicitly states that her aim is to develop a deeper conception of democratic dialogue and participation in order to ensure greater fairness and inclusion, as I will show in section 2. But Rawls, too, is clear that his conception of public reason should be conceived as a real-world method of political deliberation that should be adopted by any citizen engaged in the process of forming collective decisions about constitutional and political matters. Rawls argues at the level of ideal theory, but he expects real people to submit to the norms of public reason when they debate political issues with others for the purposes of finding a consensus on common principles and decisions, and also when they think about such issues for themselves. Rawls's political liberalism is intended at least in part as a guide to supreme court judges, 
elected representatives, executive officials, and other members of the 'formal political sphere' on how to deliberate with one another about political questions in order that the outcomes of these deliberations are considered fair (in the sense that they accord with, and support, the freedom and equality of all parties) (Parvin, 2015; Rawls, 1993). Rawls and other political liberals believe that thick ethical and cultural beliefs held by parties to the dialogue should be privatized in the sense that they should not be considered the basic subject matter of discussion. Individuals debate political issues through a process of political dialogue as informed members of particular communities, possessing interests and ideals and motivations which will be shaped by the memberships they possess and the obligations these memberships confer (Rawls, 1993; Nussbaum, 1999; Weithman, 2016). The fact that citizens will often belong to identity-conferring communities, that these communities often play a central role in shaping their ethical beliefs, and that these facts will give rise to deep diversity, is the starting point of Rawls's argument for political liberalism (Rawls, 1993). Political liberalism requires that all parties confront one another on 'reasonable' terms as part of a wider political process, which is to say that each must acknowledge that different people are reasoning from different points of view determined by the various commitments and memberships of which each is constituted, and that all parties understand all other parties as free and equal and, hence, their claims demand a fair hearing (Rawls, 1991; Parvin, 2008).

Political liberalism is thus difference-blind in the sense that it acknowledges that persons hold particular ways of life and cherish particular values and ideals, but does not require that all parties to the dialogue affirm or respect these values, or that civic and political institutions should 'treat members of different groups differently for the sake of promoting equality or freedom' (Young, 2007). Whether we understand the realm of public reason to be limited to a small number of individuals occupying roles in the formal political sphere, or whether we understand it as a much wider, more expansive forum involving the citizenry more widely, any model of political dialogue which requires each and every participant to openly and 
genuinely respect the first-order values and ends of all those others who are party to the process is in danger of merely producing stalemate. This is the core political liberal insight: that, in the face of deep disagreement, parties to dialogue can search for other, thinner, more general, grounds for consensus that keeps the dialogue from collapsing, and that they will do so.

Understood this way, the constraints that political liberals impose on public reason, and which many difference theorists in particular criticize, become less problematic. They become less obviously grounded in fundamental stipulations about what agents can and cannot do with regard to their most deeply held beliefs, and more obviously grounded in how participants in a political process who are motivated to reach agreement on difficult political questions would choose to act when faced with interlocutors who have very different beliefs to them. The constraints on citizens engaged in political dialogue become self-imposed. Rawls formulated political liberalism as a realistic approach to the concrete problem of securing stability and legitimacy in circumstances of deep diversity and he did so by focusing on what he thought people motivated to find agreement with one another would do in the service of finding this agreement.

This idea - that people would 'privatize' issues of identity and substantive belief by voluntarily imposing constraints on their own deliberations in order to reach agreement with one another - arguably unites all political or 'public reason' liberals, as well as many contractualists. Contra the claims made by many of their critics, liberals don't believe that issues of identity and culture should be ruled out of public discourse by philosophical fiat (e.g. Young, 1990; Taylor, 1994; Tully, 1995). For example, Barry, Scanlon, and Nagel have all argued for an account of political justification in which parties to political dialogue are able to appeal to those comprehensive moral conceptions of the good life which inform their understanding of the world and their place within it (Barry, 1991; Nagel, 1991; Scanlon, 1998). Similarly, Charles Larmore's political liberalism is grounded in two claims: that (a) 
questions of justice should be resolved through a deliberative process in which we seek to convince others 'of the worth of our views so that they can become part of the shared allegiances the state should promote', but, importantly, that (b) parties to the dialogue must be 'free to explain to one another in full their comprehensive visions of the good life, and not just those parts which can be laid out on the basis of common ground' (Larmore, 1995, italics added). What these and other liberals argue is that parties to the agreement process will inevitably submit to voluntary constraints on the kinds of arguments they make in the interests of reaching genuine consensus. Barry, Nagel, Scanlon, and Larmore all begin with the claim that, as far as possible, nothing should be ruled in or out of the dialogue at the outset (Larmore, 2018). Individuals have conceptions of the good which are important to them and so in principle they should be able to appeal to them during the process of determining constitutional essentials, institutional arrangements, and political decisions. This applies to ordinary citizens, but also to elected representatives and supreme court justices: such people will, like all citizens, have their own personal views on political matters which we might want to say are relevant and important. However, they say, such a substantive form of dialogue will prove incapable of producing an inclusive politics in the face of deep ethical and cultural diversity. Supreme court justices will disagree on moral questions such as abortion, as will elected representatives, and the wider citizenry. Consequently, motivated by their desire to establish such a politics, and guided by their commitment to the freedom and equality of all citizens, parties will modify their language and the reasons they give such that they are more acceptable to others. They will offer 'public' reasons, acceptable to people of divergent ethical beliefs. Judges will put aside their personal convictions and turn instead to constitution, to legal precedent, and to other areas of common agreement or expertise. Representatives will put aside ideology and partisanship, and engage with the facts of the matter and relevant evidence, and citizens will do the same. The agreement motive coupled with the norm of rational dialogue that we find in embodied in the work of Scanlon, Nagel, Barry, Larmore and others results in a conception of political dialogue initially and ideally conceived as a full blooded exchange between moral 
equals, but which - through the voluntary actions of deliberative actors genuinely seeking consensus - ends up looking not dissimilar to the model of public reason described by Rawls, a model of political dialogue which moves from the ideal to the realistic in order to resolve problems found in actually-existing states as they are found in those states (Larmore, 2018). The difference with Rawls is that he simply states it as a precondition for agreement at the beginning.

\section{The Politics of Difference and the Strategy of Politicization.}

Like political liberals, difference theorists also see their theories as addressing real problems in actually-existing states and providing a guide to citizens and members of what Rawls called the 'formal political sphere' as to how to think about political problems and resolve them. Iris Marion Young in particular is clear on this: the model of dialogue at the heart of her theory is a form of democratic, not merely hypothetical, dialogue practiced in the real world by real citizens who seek to resolve complex political problems together (Young, 2000; Tebble, 2002). That is, Young's politics of difference in particular is intended as a strategy for the reform of actually-existing states which are currently not inclusive enough, but could be. It is an argument for the 'deepening' of democracy and for the creation of new opportunities for citizens and their representatives to identify and resolve political problems, and to promote a more just society, through an expanded conception of democratic life which makes room for new and more direct forms of citizen participation alongside traditional 'public reasoning'. Young, like Rawls, is clear that the model of dialogue that she describes, and which she holds as central to her normative project, should be instantiated in real-world states and be adopted by citizens and state officials in their real-world deliberations about politics (Young, 2000). Her view as to what counts as a permissible contribution to democratic dialogue is wider than many political liberals, but she nevertheless believes that her model improves upon the liberal one in that it is more 
realistic: it captures aspects of our lived experience of politics that the Rawlsian, analytic model of public reason cannot (Young, 1990, 2000).

The problem with political liberalism, she argues, originates in the fact that liberals seek to create a regime which is impartial or neutral with regard to diverse ethical and cultural beliefs. In both Justice and the Politics of Difference and Inclusion \& Democracy, Young argued that in seeking to create a regime of institutions and principles which are impartial with regard to the specific aims and affiliations of individual members of the polity, and proposing a democratic decision making process in which think ethical and cultural beliefs are excluded, liberalism requires that persons abstract 'from all the particularities of the circumstances on which moral reason reflects.' Impartial reason, as she calls it in her earlier book, and 'objective' reason, as she calls it in her later one, aims 'to adopt a point of view outside concrete situations of action, a transcendental "view from nowhere" that carries the perspective, attributes, character, and interests of no particular subject or set of subjects' (Young, 1990; 100).

As a consequence, Young suggests that political liberalism fails on two counts. Firstly, it fails on political grounds: it fails to be impartial because we cannot be confident that assumptions drawn from our particular social position have not been smuggled into the supposedly general standpoint. Those supreme court justices might be bringing their moral beliefs to bear on political questions afterall, even if it doesn't seem like they are, and representatives might be pushing an ideological agenda when they should really be doing no such thing. Secondly, it fails on philosophical grounds: 'participants in political discussion cannot transcend their particularity' and so, in requiring them to do so, liberalism requires people to think and act in ways that they simply can't (Young, 2000; 113). Consequently, she says that we must drop the quest for impartiality and embrace a form of democratic dialogue through which real people can freely 'express their particularity to others and learn of the 
particularity of those differently situated in the world where they dwell together' (Young, $2000 ; 113)$

Young's position is grounded in a misinterpretation of political liberalism, as is hopefully obvious from the discussion in section one. The aim of political liberalism is not to construct some objectively pure political process. Rather, it is to establish a model of democratic dialogue capable of deriving substantive, fair agreement on political questions among appropriately motivated actors. Young believes that the pursuit of 'objectivity' and 'impartiality' are the same, but they are not (Young, 2000). Political liberalism seeks the latter, not the former. The claim that justice should be impartial with regard to differing conceptions of the good is not ethically neutral. It is a clear statement about the appropriate ends of liberal institutions and policies, and it is underwritten by a substantive commitment to liberal principles of freedom and equality. Consequently, it's important for political liberals that the political process isn't objectively pure, because only dialogues constrained by principles of freedom and equality will yield outcomes which might be considered fair, and which satisfy the conditions of liberal impartiality. Rawls, for example, argues that we should understand parties to public deliberation to be free, equal, and possessing sufficient 'political' autonomy to discuss their comprehensive doctrines in ways which are compelling to those who do not hold them and who may, in fact, reject them (Rawls, 1993; 78). Larmore, too, argues that public deliberation should be constrained by prior and overarching commitments to 'equal respect' and 'rational dialogue' among moral equals, and similar claims are made by other political liberals (Macedo, 1995; Nussbaum, 1999). The issue is not whether the agreement process embodies substantive principles, but whether the substantive principles it embodies are fair, whether they follow coherently from the deliberative process, and also whether alternative theories avoid invoking these (or other) principles in order to determine exactly what kind of political debates are necessary to produce normatively appropriate outcomes. Liberals can therefore agree with Young that they are guilty of importing ethical principles into their conception of impartiality and 
dialogue. Indeed, they have done so. But they can and should reject the claim that this is a problem. Liberal impartiality sets limits on what can and cannot pass as appropriate forms of political debate, and on the outcomes of that debate. And the norms of debate are in turn seen to emerge directly out of the assumed motivations of the parties to the dialogue. If people are sufficiently motivated to find agreement, they can and will voluntarily engage in forms of dialogue consistent with Rawls's conception of public reason, and which therefore produce normative outcomes which are impartial with regard to parties' comprehensive doctrines, attachments, and particular beliefs.

Furthermore, the claim that persons are unable to 'transcend their particularity' for the purposes of deriving solutions to political questions must either be false or problematic for both political liberalism and the politics of difference. Young may or may not be right that 'no-one can adopt a point of view that is completely impersonal and dispassionate, completely separated from any particular context and commitments' (Young, 1990; 103). But again, the idea of impartiality at the heart of political liberalism doesn't require anyone to adopt such a view. Indeed, political liberalism holds that personal beliefs and memberships cannot be easily 'reasoned away', which is why diversity on fundamental questions about the good life represents such an important political issue. Political liberalism, like the politics of difference, only requires that people 'transcend their particularity' in the sense that they are able to explain and justify their commitments to others who may not share them, on terms that they might understand and accept. It requires judges, representatives, and citizens more generally to establish only as much critical distance from their ends as they need in order to talk about them in a way that others might relate to.

In defending the strategy of privatization, political liberals in fact take the scale and depth of ethical disagreement more seriously than those who adopt the strategy of politicization. They adopt at a more realistic approach, and also accord cultural groups more respect, than those who believe in the politicization of difference. The problem with the strategy of 
politicization articulated by Young, but found in other thinkers too, is that it fails to attend to the fundamental reason why political liberals seek to privatize the ideas and claims which arise out of group membership. The reason they do so, as we outlined earlier, is because not doing so is simply too demanding of a diverse public. Indeed, the approach to diversity at the heart of the politics of difference would seem to accept the initial liberal ideal that we find in Barry et al of finding substantive agreement on regulative principles through a full blooded exchange of ethically thick reasons and arguments, without acknowledging their subsequent claim that such agreements will prove too demanding of those involved and that therefore an agreement process understood in such an idealized way will be incapable of yielding the kind of agreements that are required of it. Put another way, it would seem that the problem with those who advocate the politicization of difference is that they would appear to require persons to engage in exactly the kind of utopian search for consensus on the respectability and coherence of ends that political liberalism claims is impossible and, hence, strives to avoid.

A key task of political dialogue for political liberals and defenders of a politics of difference is that it is capable of determining whether the kinds of life arising out of particular group memberships are worthy of accommodation or not, based on their public justifiability. It is not to simply value or affirm the ways of life arising out of group memberships, but to evaluate the public justifiability of the sorts of ways of life conferred by group memberships in order to determine whether these ways of life should be allowed, or whether they should be eradicated. Neither political liberals nor difference theorists believe that the fact that a way of life arises out of membership in a group means that we should value it. Young herself distinguishes between 'positional' or 'structural' differences and 'cultural' ones (Young, 2007). Members of certain groups (like the poor, the uneducated, the unhealthy) suffer structural disadvantages as a consequence of their membership of these groups, and both liberals and defenders of a politics of difference believe that it is a proper concern of political institutions to rectify these disadvantages. This is because both 'sides' believe that the 
process of resolving questions of justice should be framed and constrained by prior commitments to freedom and equality. Structural inequalities in the distribution of social resources like education, wealth, healthcare, political status, and so on are, for Young and for political liberals, group-based problems that must be overcome, not protected or affirmed. Similarly, political liberals and defenders of a politics of difference are united in their view that no individual should be structurally impeded from participating in political dialogues which will produce the laws and institutions under which they live. Young claims in Justice and the Politics of Difference that members 'of a polity need not seek and arrive at agreement on a general account of justice in order to argue productively about their problems and come to morally legitimate resolutions' to political conflicts (Young, 2000, 29). But she then later states that 'political outcomes can only be considered morally legitimate if those who must abide or adjust to them have had a part in their formation' (Young, 2000, 53). 'The democratic legitimacy of a decision,' she says, 'depends on the degree to which those affected by it have been included in the decision making process and have had the opportunity to influence the outcome' (Young, 2000, 5-6). Thus for Young, as for Rawls, political dialogue is appropriately regulated by wider, pre-political ethical principles which are non-neutral and which stack the agreement process in ways which ensure certain (ethically controversial) outcomes.

Political liberals and difference theorists are thus united, not divided, on the question of whether political dialogue among judges, representatives, the wider citizens, and so on, should be conducted within constraints set by a prior commitment to substantive principles of freedom and equality. Both believe that it should, and both require that it is. Both impose normative constraints on the conduct of political dialogue and require participants to to hold certain values and not others in order to ensure against certain outcomes. Young, like political liberals, 'smuggles' substantive principles like freedom and equality into the process by which individuals identify and resolve political problems and decide on an institutional and constitutional regime. And she also assumes that parties to the dialogue are capable of, 
and willing to, distance themselves sufficiently from their own group memberships in order to discuss them in ways which non-members can understand and accept. As Young put it, participants in political dialogue must 'talk past their differences' in order to arrive at a wider, thinner consensus on fundamental matters of principle, policy, and institutional design, which is to say that, like Rawls, she believes that parties to political dialogue should be willing and able to (a) adopt a reasonable standpoint with regard to their own ends and commitments (understood as a willingness and ability to 'explain their background experiences, interests, or proposals in ways that others can understand[,] . . . express reasons for their claims in ways which others recognize could be accepted', and have an open mind about the reasons that others advance in defence of their own commitments (Young, ????)), and (b) to keep talking even when faced with apparently irreconcilable disagreement. These two facts - that parties to the dialogue must view all other parties as free and equal, and that they will adopt a reasonable perspective with regard to their own ends such that they will keep talking in the face of deep disagreement - are in both approaches crucially linked and underpinned by the prior requirement that citizens value the freedom and equality of all parties. If they don't hold other parties as free and equal, they will be less interested in reaching consensus or agreement with them, and more likely to abandon the dialogue and dismiss other parties' views as not worthy of consideration.

While Young understands herself as an opponent of political liberalism, along with many other difference theorists, it is clear that the strategies of political liberalism and the politics of difference thus share substantial normative similarities. Both are grounded in reasonableness and dialogue between citizens who are understood, and who understand each other, as free and equal. Both embody a range of assumptions which need to hold in order for the theories to work: cognitive assumptions about what citizens can and cannot think and do and, in particular, how they form political opinions and express themselves in political dialogue, and substantive assumptions about what citizens should and must believe. Furthermore, defenders of both approaches are engaged in broadly the same political 
endeavor: to derive a common regime of institutions, guided by prior commitments to freedom and equality, which will be seen as legitimate by all members of the polity irrespective of their wider identities and ways of life, and to propose a model of democratic dialogue through which citizens can resolve in a realistic way concrete problems in actuallyexisting states.

\section{The Need for a New Theory.}

I have presented political liberalism and the politics of difference as theories which take political reality seriously and which attempt to respond to the empirical fact of ethical and cultural diversity in ways which are normatively persuasive, but also realistic. However, the lived practice of politics in liberal democratic states around the world strongly suggests that the ethical and motivational assumptions built into both approaches are unrealistic, and hence, that they are unable to provide persuasive solutions to the problems that they address. That is, although they can and should be interpreted as theories which aspire to resolve real problems in liberal societies in a realistic way, they still can't do so because the pre-political cognitive and substantive commitments on which they are grounded are untenable in the contemporary era. It may be that political realists are right that the problem is the brute fact that both approaches are committed to pre-political assumptions (Geuss, 2008; Rossi, 2018; Sleat, 2018). I can't settle that argument here. Instead, I want to make a more limited point: that both political liberalism and the politics of difference are grounded in particular pre-political commitments at both the cognitive and substantive levels which are controversial in the contemporary era, and that these commitments render the form of political discourse at the heart of both theories untenable.

The reasons for this are two-fold: (a) people can't and don't reason in the ways that defenders of these approaches require, in part because (b) many people are not motivated to enshrine the underlying values of freedom and equality on which they are based. Both 
approaches are premised on the idea that free and equal citizens will in the real world engage in political dialogue with one another in the interests of reaching sufficient consensus on constitutional and institutional matters to produce a political regime that all parties accept is legitimate. They will do so as individuals, who nevertheless possess group attachments which are important to them. Motivated by their commitment to the freedom and equality of all persons, real world parties to the dialogue will voluntarily adopt a 'reasonable' perspective with regard to their own ends and values, and to the ends and values of others, in that they will engage with one another's views in good faith, take counter-arguments seriously, and be willing to change their minds when presented with compelling evidence. Even in Iris Marion Young's theory, which envisages a more dynamic, conflictual form of dialogue than that shared by liberals, parties are required to be broadly open-minded and receptive to the views of others, and to approach one another and the political process in general motivated by a good faith spirit of readiness to find consensus.

But people aren't open-minded and receptive to the views of others, at least, not in the way either theory requires. Moreover, they are often not willing or able to change their minds in light of compelling evidence, or to engage in good faith with others with whom they disagree and, hence, they are not willing or able to adopt the reasonable perspective that the strategies of politicization and privatization require. The cognitive and substantive assumptions built into each theory - that is, the assumptions each makes about individual political psychology and people's personal values - are at odds with reality and, hence, cast significant doubt on the ability of either theory to offer realistic solutions to genuine political problems, or to propose a political system which can exist in the contemporary era.

\subsection{Problems at the Cognitive Level.}

At the cognitive level, evidence from the fields of political psychology and the social and political sciences should lead us to question the grounding assumptions of liberal public 
reason about how people understand and situate themselves in the world - including the political world - and the ways in which they are willing or able to discuss political issues, or issues of deeper ethical import. People are subject to cognitive biases which hamper the kind of reasoned debate these theorists believe is necessary. They select information that confirms their own position, and are generally less sympathetic towards evidence which challenges their settled opinions (Mutz, 2006). They tend to process political information through the prism of their prior political and ethical beliefs, rather than through a reasonable engagement with evidence or facts (Huddy et al, 2013; Lodge \& Taber, 2013). They are often biased, irrational, unkind, and partial. They are subject to tribal mentalities which tend to overpower their more rational faculties. Evidence suggests that our group identities matter, but not in the way that political liberals or defenders of a politics of difference believe (Brennan, 2016; Haidt, 2012; Westen, 2008). People are partisan, and their partisan memberships confer not just opinions and values, but identities, a sense of self (Achen \& Bartels, 2016). Political liberals and difference theorists all acknowledge this fact. Indeed, it is the founding assumption of their theories, and the central motivation behind their projects. But having acknowledged it, they ignore its real world consequences.

The fact that individuals gain their identities from their membership of various groups means that they are less willing, and less able, to engage in the kind of political process that these thinkers believe is necessary, not more (Achen \& Bartels, 2016; Mutz, 2006). Political liberals and defenders of a politics of difference believe that modelling the political process by which institutional arrangements and constitutional essentials are determined as a dialogue between citizens embedded in identity-conferring groups makes their theories particularly suited to deriving consensus among diverse people. Much like contemporary epistemic democrats and some deliberative democrats, Young and Rawls both believe that political dialogue is a form of collective problem-solving; a means of pooling the on-theground insights of citizens in the service of identifying and resolving political problems (Rawls, 1993; Young, 2000; Landemore, 2017; Mansbridge et al, 2012). Dialogue reveals 
shared concerns and topics on which common consensus is possible and topics on which it is not. Because people are assumed to be motivated to find such common consensus, they will feel a pull, an incentive, to take part in good faith, which will inevitably require them in time to adopt a reasonable perspective with regard to their own values and those with whom they are debating. But in fact the opposite is true. The fact that our opinions, values, and ideals reflect, and arise out of, a deeper sense of self or identity conferred by group memberships, incentivizes our avoidance of political debate, not our participation in it. It means that there is a lot to fear from engaging in public discourse about politics: a lot to lose and little to gain. By entering into political discourse - especially the kind required by political liberals and difference theorists - we place ourselves in a vulnerable position, a position in which we are encouraged to question our views and ideals, to change our minds, and perhaps to realise that our deepest beliefs are grounded in error and need to be abandoned.

If our deepest beliefs are shaped, or even determined, by some wider sense of identity drawn from our membership of partisan groups, then questioning our views involves questioning the identity that gave rise to them. It requires us to reflect not just on what we think, but who we are. Moreover, rejecting or even questioning the prevailing wisdom of the social groups to which we belong brings a range of negative consequences for us: we may lose the respect of other members, our social standing within the group may decline, we may be ridiculed or subject to harsh judgement. We may feel embarrassed or ostracized. We may no longer feel that I fit in.

The fact that contradicting the collective view of the groups to which I belong and questioning the views of the people around me who I may like and respect can give rise to social sanction and a deeper crisis of identity at least partly explains why so much of contemporary political debate is characterised not by consensus or reasonable debate in pursuit of shared commitments, but by anger, frustration, and ideological entrenchment. If I draw my identity or sense of self even partly from my membership of a political movement or 
group which views climate change as a fiction, for example, then I have a strong vested interest in not subjecting that view to much scrutiny (Caplan, 2007). To question that view would be to question who I am and what my political identity is. I would have a strong personal interest in ignoring alterative views and contrary evidence, and avoiding political dialogue with people who disagree with me (Mutz, 2006). And I would have a strong personal interest in speaking only to like-minded individuals who believe the same things as me and who did not force me to question my values and ideals and, hence, cause me to reflect too deeply on who I am more generally (Achen \& Bartels, 2016). So it proves. Our membership of social social networks of like-minded individuals builds identity and selfconfidence and insulates us from having to engage genuinely with people with whom we disagree, to listen to them, or to take them seriously. This is not the same as voluntarily putting aside controversial matters in order to reach consensus. Indeed, real world citizens seem to do half of what is required of them by political liberals and difference theorists: they rule out certain issues as inadmissible on account of the fact that they are too controversial or divisive, but they fail to then seek wider grounds for consensus. The move required by Young and Rawls - that people will keep talking in the face of deep disagreement and will therefore voluntarily adopt a reasonable perspective with regard to their own ideals and the ideal of others, and offer reasons acceptable to all - will not happen.

The politics of liberal democratic states is characterized in part by unresolved differences of opinion, political polarization, ideological entrenchment, and incivility. And it is characterized also by the absence of a wider process by which these things might be resolved. Numerous 'democratic innovations' have been proposed by academics to better facilitate the kind of reasoned dialogue presupposed and required by democracy including, for example, deliberative polling, citizens' assemblies, and other 'minipublics' (e.g. Fishkin, 1991; Fung, 2007). For all their differences, these innovations are united in that they all seek to artificially construct the conditions necessary for appropriate citizen participation, and foster deliberative competences in citizens, which do not exist in society, or in citizens, at large. 
Minipublics are specifically designed to compensate for the cognitive and substantive failings of citizens (Warren \& Gastil, 2015). Defenders suggest that the qualified success of minipublics in producing deliberation more akin to that envisaged as necessary by political liberals suggests that the people can deliberate, and that the cognitive and substantive failings of citizens is not the problem I suggest it is. But in fact the opposite is true: the need for minipublics proves how difficult it is to establish the right kind of dialogue in a democracy: it can only exist in purpose-built environments away from the wider society, under tightly controlled conditions. Minipublics are necessary and helpful in so far as they allow the existence of a deliberative space which exists nowhere else. Whether or not minipublics are a welcome move, they do little to ease the concerns of those of us who take cognitive and substantive deficits in citizens seriously. At the very least, a democracy which relies on minipublics to structure political dialogue departs very far from the kind of grassroots, bottom-up approach envisaged by Young, and would inevitably see appropriate political debate as something that can only occur away from the general population, at a distance from citizens as they are in the wild.

What is lacking then, is any clear strategy for dealing with citizens' cognitive failings at the level of society at large. No such process exists, or perhaps can exist. This is particularly evident regarding questions surrounding immigration and cultural diversity. Citizens of contemporary states are deeply divided over what should be done about immigration, about how many immigrants - if any - should be permitted to cross their borders, and also about how immigrants should be expected to act once they have done so. Political debate about immigration doesn't resemble the kind of debates described by Rawls or Young (or by many of the deliberative and other kinds of democrats who have drawn inspiration from them). It's not characterised by a spirit of agreeing to disagree, or of a pragmatic putting-aside of insoluble differences in the interests of building a wider consensus. It doesn't look like a problem-solving exercise in which citizens pool their insights in the service of resolving difficult issues. Instead, it resembles an abandonment both of dialogue and of the desire for 
consensus. Defenders of the strategies of privatization and politicization presuppose and require that citizens will, when faced with intractable disagreement, voluntarily impose constraints on the way they discuss the issues at hand in order to reach consensus. This is because they assume that individuals will be motivated to keep talking in light of profound disagreement. But people tend not to do this, and are not sufficiently motivated to keep talking in the face of profound disagreement. Instead, they disagree, and then give up on the dialogue. Political debate collapses and we are left with no consensus or even any desire for consensus; we are left with the entrenchment of different perspectives and the absence of a meaningful process by which differing views might be reconciled. We are left instead with, at best, stalemate, and, at worst, deep social and political conflict.

Some may argue that the fact that the current politics of liberal democratic states doesn't live up to the kind of political process envisaged by political liberals or difference theorists, doesn't mean that those theories are wrong. Contingent facts about the lived reality of politics in many liberal democratic states can't undermine the normative persuasiveness of either theory. But these aren't contingent concerns: these are matters which concern the deep philosophy of both political liberalism and the politics of difference. The inability of actually-existing states including the UK, the USA, and many of the democracies of Europe to resolve complex and divisive issues such as immigration are surely in part attributable to policy and institutional failures. But they are also a result of important facts about people, their motivations, and the way they process and discuss political issues. At base, political liberalism and the politics of difference presuppose and require citizens to engage in forms of dialogue that empirical evidence strongly suggests that they can't or won't engage in. There are many possible reasons for this (Parvin 2015, 2018a, 2018b). Some concern the empirical circumstances in which people find themselves: citizens without access to certain key civic, social, and intellectual resources tend to develop less democratic capacity than those who do have access to them, which is why political participation tends to be concentrated among the advantaged middle classes, and why the agendas of liberal 
democratic states disproportionally reflect the concerns of this group (Brennan, 2016; Knight \& Johnson, 1998; Putnam, 2001). It also partially explains differences in 'reasonableness' across different states, which exhibit different levels of equality. But the cognitive factors which shape citizens' participation in political discourse are widespread, and widely studied (e.g. Converse, 1964; Haidt, 2012; Westen, 2008). Lack of access to socio-economic and civic resources merely exacerbates their effects, and serves to concentrate their negative consequences among citizens of a low socio-economic status (Bartels, 2008; Birch, 2014; Cohen \& Sabel, 1997; Gilens, 2014; Skocpol, 2004; Solt, 2008). The issue can thus be helped, and their effects equalized, by initiatives aimed at reducing social and economic inequality, as I have argued elsewhere, but they cannot be eradicated entirely.

\subsection{Problems at The Substantive Level}

Political liberalism and the politics of difference are ill-equipped to resolve conflicts about political opinions. They are even less able to resolve conflicts about cultural and ethical values, which is their central purpose. Political liberals are right that the content of citizens' cultural and religious beliefs cannot be refuted by appeals to rational evidence and facts. But they are wrong in thinking that this will mean that citizens will modify their stance and reframe their discussion in terms of an exchange of public reasons. This move, which we also see in difference theory, requires that citizens are genuinely motivated to reach consensus with their interlocutors and also that they view them as equal to them, and free, and hence respect them enough to keep talking in the face of profound disagreement. The problem is that they often don't. The politics of the early $21^{\text {st }}$ Century has revealed all too clearly that many citizens don't see members of other cultures, or holders of other beliefs, as equal to them, or the kind of people that they want to reach consensus with. Majorities have become much more hostile to minority identities and practices (Parvin, 2017). Citizens have become fearful of the effects that immigration and diversity will have on social unity, on shared values, and on public services. They often do not hold to the assumption, found in political 
liberalism and the politics of difference, that the needs and beliefs of diverse minority communities should be respected and tolerated and that, therefore, they need to design a constitutional and institutional regime in which minority groups are able to participate in their cultural practices and to pursue the conceptions of the good that arise out of their cultural or religious memberships on a free and equal basis. The fact that citizens are beset by cognitive factors which thwart their ability to engage in reasonable political discourse premised on the sharing of public reasons is sufficient on its own to weaken both political liberalism and difference theory. However, they also often hold values and ideals which mean that they will not be willing or able to participate in the kinds of political discourse we find in these approaches.

Recall, Rawls's theory is premised on the idea that the vast majority of the citizens of liberal democratic states will be reasonable in at least the sense that they are

'ready to propose principles and standards as fair terms of cooperation and abide by them willingly, given the assurance that others will likewise do so. Those norms they view as reasonable for everyone to accept and therefore as justifiable to them; and they are ready to discuss the fair terms that others propose' (Rawls, 1993, 49)

Reasonable persons 'are not moved by a general good as such, but desire for its own sake a social world in which they, as free and equal, can cooperate with others on terms all can accept' (Rawls, 1993, 50). The 'unreasonable' are considered a problematic minority who, unfortunately, will exist but who can, on account of their minority status, be relatively easily and justifiably subject to political repression. There will always be oddballs, cranks, and zealots whose commitment to unreasonable comprehensive doctrines puts them beyond the scope of public reason. There is, Rawls seems to think, not much one can say about these kinds of people: people who will, for whatever reason, fail to engage in the process of public reasoning in the way Rawls believes people should, or who hold beliefs, ideals, or principles 
which run contrary to public reason and - on liberal grounds - can be legitimately coerced into conforming to the consensus arrived at by their more reasonable fellow citizens. The problem, of course, is that in the current political climate, unreasonable people actually make up a significant proportion of liberal societies. They might, in some states, make up the majority. Rawls's theory has often been criticized for its apparent inability to cope with 'the unreasonable', that is, the people who can't or won't do or think what the theory requires. Defenders have traditionally fended off such criticism by pointing out that no theory can cope with the lunatic fringes, and further, that no liberal theory should be required to wholly inclusive of all comprehensive doctrines, including deeply illiberal ones (Quong, 2010). But this defence becomes less persuasive when we realise we are not merely talking about a few illiberal extremists at the peripheries of society, but the broad mass of the citizenry. The fact that Rawls and many political theorists who have followed him in positing the value of the dialogical model, have continued to understand the class of citizens considered 'unreasonable' as a small minority is perhaps the clearest example of the vast disconnect that currently exists between mainstream political theory and the real politics of actually-existing states, and is thus perhaps the clearest indication that political theorists need to revisit some of their core assumptions and methods.

According to a recent survey, 1 in 5 Americans (around 50 million people) believe that Muslims should be denied the right to vote. $42.3 \%$ of Americans - and $87 \%$ of Republicans - approve of a President who has described immigrants as 'vermin' intent on 'infesting' the country, and who has also publicly advocated the suspension of the rule of law by calling for the summary deportation of immigrants attempting to cross the US/Mexico border 'immediately and with no court cases or judges' (Swaine, 2018). In the UK, 77\% of citizens claim that migration from the Arab world has not been beneficial to the UK, and a majority (55\%) support racial profiling for Arabs and Muslims 'for security reasons'. The same number believe that the values of Islam are incompatible with British values (YouGov, 2017). Across Europe populist movements - characterised by fierce anti-immigration, anti- 
globalisation, and pro-nationalist policy agendas - have attracted considerable support among vast numbers of citizens. In 2017, the far-right Alternative for Germany (AfD) became the third largest party in the country, claiming 94 seats in the Bundestag having pledged to protect Germany from 'an invasion of foreigners from a different culture' - the first time in 60 years that a far-right party has moved into the federal parliament. In the Netherlands, Geert Wilders, leader of the Party for Freedom, described Moroccan immigrants as 'scum' and publicly called for the banning of the Koran and the closing of mosques and Islamic schools. The party came second in the 2017 elections. Poland's Laws and Justice party easily secured victory in the country's 2015 parliamentary elections, taking nearly $40 \%$ of the vote on a fiercely anti-immigration platform. In Greece, Neo-Fascists Golden Dawn are now the country's third largest party, and France's National Rally (formerly National Front), whose leader warned of the 'subjugation' of France by Islam and globalization, narrowly missed out on power in 2017.

While populism hasn't yet taken hold in Europe in the way many feared it would, it's clear that this has been largely due to the fact that many mainstream parties have shifted to the right in order to appeal to supporters of populist parties. Just as both the Labour party and the Conservatives in the UK adopted a much stricter stance on immigration and national values in 2015 in order to counter the likely right wing insurgency by the UK Independence Party, so mainstream parties across Europe have done the same. The failure of right wing parties to break into the political mainstream in Europe hides the deeper fact that the general populations of these countries have shifted to the political right on issues of cultural diversity and immigration and now hold views which run counter to, and are problematic for, the kind of inclusive politics defended by the vast majority of political theorists, including political liberals and defenders of a politics of difference. Many citizens across many of the world's most advanced liberal democratic states are 'unreasonable' in the Rawlsian sense that they hold values which preclude them from engaging in the form of public reason on which the theory rests. 
Again, this is a foundational rather than a contingent problem. The central premise of difference theory and political liberalism is that we should take the values and ideals that actual people in the world hold seriously. The values of citizens can't and shouldn't be wished away in order to make the project of resolving political problems and making political decisions easier. Both difference theorists and political liberals take as their starting point the fact that people will hold values which are important to them, that these values will not be relinquished as a result of rational debate, and that therefore we need to design a political system based on the fact of their existence and which can manage their existence and the conflicts that will inevitably occur between them. So the fact that, in the real world, vast numbers of citizens hold values which preclude them from engaging in the kind of dialogues these theories require is fundamentally important, and also a foundational critique of both approaches. Political liberalism and difference theory are both offered as strategies for dealing with real world diversity, and they are defended by their advocates on the grounds that they take the fact of real world diversity seriously. But they both fail to do so. Citizens don't think or act in the ways that these theories require, and vast numbers of them hold beliefs which, if taken seriously (as both theories believe we should), mean they can't in good faith participate in the political process envisaged in either approach. Both approaches are so concerned with a certain narrow range of empirical problems (i.e. those associated with managing cultural and ethical diversity) that they are blinded to the significance of others: their responses to the normative challenges posed by the empirical fact of cultural and ethical pluralism are undermined by the normative challenges posed by other empirical facts about our contemporary political predicament. The cultural and ideational landscape of the early $21^{\text {st }}$ Century, observable in the vast majority of contemporary liberal democratic states, does not support either of the approaches that emerged as dominant in first wave debates about multiculturalism. 


\section{A Stark Choice.}

If we want a realistic normative response to cultural and ethical pluralism, therefore, we should reject the assumption that individuals will be motivated to engage in public reasoning with others or that, when faced with deep disagreement, they will impose voluntary constraints on their deliberations in the interests of finding consensus. Instead, we should ground our theories in people as they are: as generally unwilling to engage in political dialogue, or to expose themselves to views or evidence which will challenge their own ideas, their own sense of self, and who hold to values which are different to the values they are assumed and required to hold by difference theorists and political liberals. People are motivated to avoid political debate, not to seek it out, just as they are motivated to avoid, rather than seek out, evidence or facts which undermines their views (Achen \& Bartels, 2016; Brennan, 2016; Caplan, 2007; Mutz, 2006;). And they often don't see others as equal to them, or believe that others should be free to practice their beliefs in the way both approaches require. The basic assumption at the heart of all these approaches - that individuals' ideals and 'conceptions of the good' are importantly shaped by their group memberships - is precisely what renders them problematic. The empirical fact of ethical and cultural diversity undermines the efficacy of public reasoning, and its appeal for citizens, as a means of resolving the issues that it is charged with resolving. Taking the felt and expressed beliefs of real people seriously doesn't support the adoption of either the strategy of privatization or of politicization. It instead presents political theorists with a choice between two very different courses of action, the implications of which go beyond questions of cultural diversity. It essentially requires theorists to make a choice between the value of democracy and the value of justice.

On the one hand, they could choose justice. That is, they could accept that in order to ensure that cultural and other minority groups are treated in ways which are consistent with basic principles of freedom and equality in the real world, they need to either abandon 
democratic dialogue, or dramatically reduce its importance in their theories. They could acknowledge that the only way a dialogue-based theory can produce outcomes congruent with principles of freedom and equality is if they model the dialogue in a way that requires too much of citizens and subordinates the motivations, abilities, and values of real people to the often noble, yet fictitious, motivations and values of mythical people. The more work that the idea of dialogue that we find in these theories is required to do, the more central it is to them, the less able the theory will be to derive normative prescriptions, or to solve political problems, in ways which can be applied in the real world.

The practical outcome of this approach would be the evisceration of much of democracy's normative content and the move away from the kind of participatory or deliberative forms of democracy that are currently popular among many political theorists, toward a more minimal form of democracy premised on the formal right of all individuals to participate in the political system. Even this would be controversial in some states, as we have seen that many people believe that members of certain minority groups should be stripped even of the basic political liberties to participate in democratic elections. Political reality doesn't allow the possibility of a society which supports and protects the substantive equality and freedom of all its members in the way difference theorists and many liberals require and a richer, more participatory form of democracy than we currently have. Political reality requires that if we want a more just society which protects every individual's freedom and equality, we must empty democracy of much of its content in order that it could be easily subordinated to the demands of a prior commitment to these two principles. Young has a very rich, expansive view of what democracy in the real world should look like and what we can expect it to do. In particular, she believes that the democratic process is a fitting mechanism for revealing what a basic commitment to freedom and equality requires in any given society: the demands of freedom and equality are revealed by citizens collectively engaging in democratic debate and political action. But Young already claims she knows what a commitment to freedom and equality requires: it requires the respect of difference, differential treatment of different 
groups, and an inclusive public sphere. Empirical evidence strongly suggests that democratic dialogue among real citizens in real states would in fact be a very poor mechanism for generating anything like such a regime, and that it would be much more likely to produce a system characterised by inequality, intolerance, and exclusion. To produce outcomes which are fair and consistent with freedom and equality the democratic process would have to be heavily circumscribed by the principles of freedom and equality, principles which gain their legitimacy independently of the process. The democratic process may be a good mechanism for working out the specific requirements of a prior commitment to freedom and equality among the parties to the dialogue. But it is not a good mechanism for producing outcomes which are consistent with freedom and equality if many citizens reject these values, as they currently do.

A number of political theorists have understood democracy as subordinate to, or a mere instrument of, justice (e.g. Van Parijs, 2011). But favouring justice in this way would be very controversial, not least because it would call for the resolution of political problems on the basis of independently stipulated principles of justice over and above the expressed wishes of citizens. Citizens could be involved in the political process but in any dispute between what a commitment to justice (understood as a commitment to substantive equality and freedom) would require, and what democracy would require, justice would necessarily have to win. Citizens would have little or no influence, no significant role, in the making of decisions or the identification of political problems: democratic politics would in practice be little more than the systematic application of principles of justice to real world problems, problems which were themselves identified through the prism of the theory itself.

On the other hand, political theorists can remain committed to the idea that political decisions should emerge out of genuine political dialogue among citizens, but they must accept that doing so will almost certainly result in decisions (as well as institutional and constitutional arrangements) which are very different to the ones that many theorists defend, 
and which they themselves might defend. It would require recalibrating the form that the dialogue takes, and taking people's actual motivations seriously, rather than requiring them to be motivated in ways they are not, including requiring them to participate in the dialogue in the first place. It would require building normative principles, as well as resolving political problems, from the raw materials provided by empirical political and social science, and using them to design a political process which can provide solutions to enduring problems which real people, with all their idiosyncrasies, frailties, and incoherences, will find acceptable. Such an approach would be 'fact-dependent', to use David Miller's words (Miller, 2013). It would be grounded in the idea that action-guiding normative principles, if they are to speak to real-world problems, must be built on 'the basis of beliefs that people hold to begin with, and in the light of the actual circumstances they find themselves in, rather than some imaginary world whose natural and social laws are different to our own' (Miller, $2013 ; 4)$.

Choosing the second option would require political theorists to be significantly more modest in the normative prescriptions they defend, and the visions of politics that they present. A political process understood in terms of a strong notion of democracy modelled as a genuine debate between parties as we know them to be could well look very different to the ones that many egalitarian liberals defend, and may embody principles which many political philosophers wouldn't support. Miller calls such an approach 'contextualist' (Miller, 2013). Others have called it 'realist' (Geuss, 2008; Runciman, 2012; Sleat, 2018). Whatever the differences between these two approaches, they both signal the need to resolve real world issues by grounding our normative theorizing in the world as it is presented to us, using the tools we have available, rather than engaging in wishful thinking. Such an approach would produce a consensus more fragile than that envisaged by either political liberals or defenders of a politics of difference. It would also represent a way of doing political philosophy that many philosophers would reject, a way which rejects the analytic method of 
putting aside contingent experience and empirical facts, and which instead embraces contingency, context, and the incorporation of reality at base (Parvin, 2011).

\section{Conclusion.}

In the introduction, I mentioned that questions of methodology and realism have moved to the foreground of normative political theory. Political theorists increasingly seek to analyse not only the substantive content of our political lives but the ways in which we should analyse politics. The radical transformation in public attitudes about immigration and cultural diversity across the world makes such methodological theorizing crucial. If political theory is to speak to real world problems, it needs to take into account changes in the real world and build them into the practice of normative theorizing. I've suggested in this piece that this may involve a choice that many political philosophers may find unpalatable, a choice between establishing a just society which treats members of minority cultures as free and equal, and which resolves matters of policy and institutional design by consulting first principles which gain their legitimacy independently of the democratic process, and a democratic society which seeks, as far as possible, to enact the will of the people as expressed through some form of public dialogue. More deeply, it involves a choice between producing an idealized theory, which describes a just society which is all but unobtainable in the contemporary era, and a realistic theory which is characterised by various forms of injustice but which more closely accords with the prevailing views of many actually-existing citizens. The new and emerging political realities revealed by the dawning of the $21^{\text {st }}$ Century, coupled with growing evidence about human psychology and behavior, throw into doubt long-standing assumptions about the right way to do political theory, what it means for political theory to be realistic, and how, more specifically, actually-existing liberal democratic states might respond to the fact of cultural and ethical diversity. This last question is especially divisive and, hence, particularly revealing in this way. Neither option I presented in the foregoing section is easy, not least because in confronting the question about how best to respond to 
cultural and ethical diversity, political theorists are forced to confront hard questions about the aims of their discipline, and what means of political theorizing best helps them achieve those aims. Debates in political philosophy about the tension between justice and democracy are longstanding. The search for a realistic normative response to cultural and ethical diversity which can be applied to an increasingly anti-immigration and anti-diversity era, reveals that this tension is more intractable, and the choice between them more tragic, than many political philosophers believe.

\section{Bibliography}

Achen, C. H. \& Larry M. Bartels (2016) Democracy For Realists: Why Elections Do Not Produce Responsive Government (Princeton University Press).

Barry, B. (2001) Culture \& Equality: An Egalitarian Critique of Multiculturalism. Cambridge: Polity Press, 2001.

Barry, B. (1991) Justice as Impartiality (Oxford: Clarendon Press).

Bartels, Larry. 2008. Unequal Democracy: The Political Economy of the New Gilded Age. Princeton, NJ: Princeton University Press.

Birch, Sarah. 2014. 'Addressing Turnout Inequality', PSA political Insight blog: https://www.psa.ac.uk/insight-plus/blog/addressing-turnout-inequality

Blair, T. (2006) 'Multiculturalism and Integration', speech given to the Runymede Trust, $8^{\text {th }}$ December.

Brennan, J. (2016) Against Democracy (Princeton, NJ: Princeton University Press).

Cameron, D. (2011) Prime Minister's Speech at the Munich Security Conference, Delivered $5^{\text {th }}$ Feb. Available: https://www.gov.uk/government/speeches/pms-speech-at-munichsecurity-conference

Cohen, J. \& C. Sabel. 1997. 'Directly-Deliberative Polyarchy', European Law Journal 3/4, pp. $313-342$.

Converse, P. E. (1964) 'The Nature of Belief Systems in Mass Publics', in D. E. Apter (ed) Ideology and Discontent (London: Free Press of Glencoe).

Fishkin, J. (1991) Democracy and Deliberation: New Directions for Democratic Reform (New York: Yale University Press). 
Fraser, Nancy. 1990. 'Rethinking the Public Sphere: A Contribution to the Critique of Actually Existing Democracies', Social Text 25/26, pp. 56-80

Fung, A. (2007) 'Minipublics: Deliberative Designs and Their Consequences', in S.W. Rosenberg (ed) Deliberation, Participation, and Democracy (London: Palgrave Macmillan), pp. 159-183.

Gaus, G. (2012) The Order of Public Reason: A Theory of Freedom and Morality in a Diverse and Bounded World (Cambridge: Cambridge University Press).

Geuss, R. (2008) Philosophy and Real Politics (Princeton, NJ: Princeton University Press).

Gilens, M. (2014). Affluence and Influence: Economic Inequality and Political Power in America (Princeton, NJ: Princeton University Press)

Gray, J. (2000) Two Faces of Liberalism (Cambridge: Polity Press).

Haidt, J. (2012) The Righteous Mind: Why Good People are Divided by Politics and Religion (New York: Pantheon).

Horton, J. et al eds. (2018) The Political Theory of Modus Vivendi (London: Springer).

Huddy et al (2013) 'Introduction', in The Oxford Handbook of Political Psychology, Huddy et al (eds) (Oxford: Oxford University Press), pp. 1-21.

Knight, Jack \& James Johnson. 1998. 'What Kind of Political Equality Does Deliberative Democracy Require?', in James Bohman \& William. Rehg (eds) Deliberative Democracy: Essays on Reason and Politics. Cambridge, MA: MIT Press.

Kymlicka, W. (2007) Multicultural Odysseys: Navigating the New International Politics of Diversity. Oxford: Clarendon Press.

Kymlicka, W. (1997) Multicultural Citizenship: A Liberal Theory of Minority Rights (Oxford: Clarendon Press).

Kymlicka, W. (1989) Liberalism, Community, and Culture (Oxford: Clarendon Press).

Laden, A. \& D. Owen (eds.) (2007) Multiculturalism and Political Theory. Cambridge: Cambridge University Press.

Landemore, H. (2017) Democratic Reason: Politics, Collective Intelligence, and the Rule of the Many (Princeton, NJ: Princeton University Press).

Larmore, C. (1995) The Morals of Modernity (Cambridge: Cambridge University Press).

Larmore, C. (1987) Patterns of Moral Complexity (Cambridge: Cambridge University Press).

Lodge, M. R. \& C. S. Taber (2013) The Rationalizing Voter (Cambridge: Cambridge University Press).

Macedo, S. (2000) Diversity and Distrust: Civic Education in a Multicultural Democracy (Cambridge: Harvard University Press, 2000).

Maclntyre, A. (1981) After Virtue (London: Duckworth). 
Mansbridge, J. et al. 2012. 'A Systemic Approach to Deliberative Democracy', in J. Mansbridge \& J. Parkinson (eds) Deliberative Systems. Cambridge: Cambridge University Press, pp. $1-26$.

Meer et al eds. (2016) Multiculturalism and Interculturalism: Debating the Dividing Lines (Edinburgh: Edinburgh University Press).

Miller, D. (2013) Justice for Earthlings (Cambridge: Cambridge University Press).

Modood, T. (2013) Multiculturalism. $2^{\text {nd }}$ Edition (Cambridge: Polity Press).

Mutz, D. (2006) Hearing the Other Side: Deliberative vs. Participatory Democracy (Cambridge: Cambridge University Press).

Nagel, T. (1991) Equality and Partiality (Oxford: Oxford University Press).

Nussbaum, M. (1999) 'A Plea for Complexity' in Joshua Cohen, Matthew Howard, \& Martha Nussbaum (eds.) Is Multiculturalism Bad for Women? (Princeton, NJ: Princeton University Press).

Okin, S. M. (1994) ‘Political Liberalism, Justice, and Gender’ Ethics 105, p. 23 - 43.

Parekh, B. (2000) Re-Thinking Multiculturalism: Cultural Diversity and Political Theory. Basingstoke: Palgrave Press.

Parvin, P. (2018) 'Representing the people: British democracy in an age of political ignorance', Political Studies Review. Published online: http://bit.ly/2pgkBCQ.

Parvin, P. \& B. Saunders (2018) 'The ethics of political participation: Democracy and engagement in the $21^{\text {st }}$ Century', Res Publica 24/1. Published online: http://bit.ly/2DtWo1P

Parvin, P. (2018) ‘Democracy without participation: A new politics for a disengaged era', Res Publica. Published online: http://bit.ly/2j5rZ1q

Parvin, P. (2017) 'Idealism, realism, and immigration: David Miller's Strangers in Our Midst', Critical Review of International, Social, and Political Philosophy 20/6. Published online (2016): http://bit.ly/2gTRVvL.

Parvin, P. (2015) 'Is deliberative democracy feasible? Political disengagement and trust in liberal democratic states', The Monist, 98/4. Published online: http://bit.ly/2F8j3Ba

Parvin, P. (2009) 'Identity and integration in an international context: Problems and ambiguities in the new politics of multiculturalism', Political Studies Review 7/3. Published online: http://bit.ly/2ryOjHN

Parvin, P. (2008) 'What's Special About Culture? Identity, Autonomy, and Public Reason', Critical Review of International, Social, and Political Philosophy 11 (3), pp. 315 - 334.

Patten, A. (2014) Equal Recognition: The Moral Foundations of Minority Rights (Princeton, NJ: Princeton University Press).

Putnam, R. D. (2001) Bowling Alone: The Collapse and Revival of American Community (New York: Simon \& Schuster). 
Phillips, T. (2004) ‘Britain Must Scrap Multiculturalism' by Tom Baldwin and Gabriel Rozenburg in The Times, April $3^{\text {rd }}$. Available from:

http://www.timesonline.co.uk/tol/news/uk/article1055221.ece

Quong, J. (2010) Liberalism Without Perfection (Oxfords: Oxford University Press).

Rawls, J. (2001) Justice as Fairness: A Re-Statement (London: Belknap Press).

Rawls, J. (1993) Political Liberalism (New York: Columbia University Press).

Rawls, J. (1971) A Theory of Justice (Oxford: Oxford University Press).

Raz, J. (1986) The Morality of Freedom (Oxford: Clarendon Press).

Rossi, E. (2012) 'Justice, Legitimacy, and (Normative) Authority for Political Realists', Critical Review of International, Social, and political Philosophy’, 15/2, pp. 149-164.

Runciman, D. (2012) 'What is Realistic Political Philosophy?', Metaphilosophy 43/1-2, pp. 58-70.

Sandel, M. (1982) Liberalism and the Limits of Justice (Cambridge: Cambridge University Press).

Scanlon, T. (1998) What We Owe To One Another (Cambridge, MA: Harvard University Press).

Skocpol, T. (2004) 'Civic Transformation and Inequality in the Contemporary United States', in Kathryn Neckerman (ed) Social Inequality. New York: Russell Sage Foundation.

Sleat, M. (2017) Liberal Realism: A Realist Theory of Liberal Politics (Manchester: Manchester University Press).

Sleat, M. ed. (2018) Politics Recovered: Realist Thought in Theory and Practice (New York: Columbia University Press).

Solt, Frederick. 2008. 'Economic Inequality and Democratic Political Engagement', American Journal of Political Science 52/1, pp. $48-60$.

Stemplowska, Z. \& A. Swift (2012) 'Ideal and Non-Ideal Theory', in D. Estlund (ed.) The Oxford Handbook of Political Philosophy (Oxford: Oxford University Press).

Taylor, C. (1994) 'The Politics of Recognition', in Amy Gutmann (ed) Multiculturalism and the Politics of Recognition (Princeton, NJ: Princeton University Press), p. 25 - 74.

Tebble, A. (2017) Epistemic Liberalism: A Defence (London: Routledge).

(2002) 'What is the Politics of Difference?' Political Theory 30/2, pp. 259-281.

Tully, J. (1995) Strange Multiplicity: Constitutionalism in an Age of Diversity (Cambridge: Cambridge University Press).

Thomassen, L. (2017) British Multiculturalism and the Politics of Representation (Edinburgh: Edinburgh University Press). 
Toynbee, P. (2004) 'Why Trevor is Right'. The Guardian, Wednesday April $7^{\text {th }}$. Available from: http://www.guardian.co.uk/politics/2004/apr/07/society.immigration

Valentini, L. (2012) 'Ideal vs Non-Ideal Theory: A Conceptual Map', Philosophy Compass 7/9, pp. 654-664.

Weithman, P. (2016) Rawls, Political Liberalism, and Reasonable Faith (Cambridge:

Cambridge University Press)

Westen, D. (2008) The Political Brain: The Role of Emotion in Deciding the Fate of the Nation (New York: Perseus Books).

Warren, M.E. \& J. Gastil (2015) 'Can Deliberative Minipublics Address the Cognitive Challenges of Democratic Citizenship?', The Journal of Politics 77/2, pp. 562-574.

Young, I. M (2007) ' Structural Injustice and the Politics of Difference', in A.S. Laden \& D. Owen (eds) Multiculturalism and Political Theory (Cambridge: Cambridge University Press), pp. 60-88.

(2000) Inclusion and Democracy (New York: Oxford University Press). University Press).

(1990) Justice and the Politics of Difference (Princeton, NJ: Princeton ${ }^{1}$ I am following Iris Marion Young in understanding Taylor's 'politics of recognition' as a
particular form of the politics of difference. See Young (2000), p. 104. 